\section{ORGANISATION OF PAEDIATRIC EMERGENCY CARE IN EUROPE}

J.-C. Mercier ${ }^{1}$, I. Maconochie ${ }^{2}$, J. Benito Sanchez $^{3}$, L. Da Dalt ${ }^{4}$, A. Gervaix ${ }^{5}$, G. Eisler ${ }^{6}$, H. Moll ${ }^{7}$, A. Martinot ${ }^{8}$, M. Ryan ${ }^{9}$, Working Group on Paediatric Emergency Care

${ }^{1}$ Service d'Accueil des Urgences pédiatriques, Hopital Robert Debré, Université Paris Denis Diderot, Paris, France, ${ }^{2}$ Paediatric Emergency Care, Saint Mary's Hospital, London, UK, ${ }^{3}$ Paediatric Emergency Care, Hospital Cruces, University Basque Country, Bilbao, Spain, ${ }^{4}$ Paediatric Emergency Care, Universita di Padova, Padova, Italy, ${ }^{5}$ Service d'Accueil et d'Urgences Pédiatriques, Hôpitaux Universitaires de Genève, Genève, Switzerland, ${ }^{6}$ Children's Emergency Clinic, Karolinska Institutet, Astrid Lindgren Children's Hospital, Stockholm, Sweden,

${ }^{7}$ Paediatric Emergency Care, Sofia Kinderhuis, Erasmus University, Rotterdam, The Netherlands,

${ }^{8}$ Service d'Accueil des Urgences Pédiatriques, Hopital Jeanne de Flandre, CHRU de Lille, Lille, France, ${ }^{9}$ Paediatric Emergency Care, Alder Hey Children's NHS, Liverpool, UK

Paediatric Emergency Medicine (PEM) is a relatively new and rapidly evolving subspecialty, and in other parts of the world it is now established as a Board-certified paediatric subspecialty. In Europe, PEM has been growing in many countries, even if very heterogeneously. In the UK, PEM has received official recognition in 2003. In France, Italy, Spain, Switzerland, and Sweden, PEM is not yet recognised, but it is practised by an increasing number of paediatricians in $3^{\text {rd }}$-level Paediatric Emergency Departments.

A WG on PEM convened in Paris on $18-19^{\text {th }}$ September 2009 with the aim of writing an European Training Syllabus on PEM to be approved by both the European Academy of Paediatrics (EAP) and the Multiple Joint Committee (MJC) on EM. During the meeting, the various organisations of PEM were reviewed in the above-listed countries.

Although the organisation of PEM was very heterogeneous between the various countries, some common features emerged: 1) the wide range of pathologies from life-threatening to self-limiting; 2) the increasing attendance, particularly at nights and the week-ends, reflecting a lower coverage of primary care; 3 ) the impact of winter epidemics (eg, bronchiolitis, gastro-enteritis, influenza A H1N1
(2009) on the attendance; 4) the critical importance of a good triage system and timely clinical-making decision; 5) the necessary good communication between PEM physicians and other hospital specialists including paediatric surgeons.

Thus, the approval of the European Training Syllabus on EM by both the EAP and MJC on EM should help develop PEM throughout the EU on more homogeneous grounds.

\section{2}

\section{IS THE PAEDIATRIC APPENDICITIS SCORE A USEFUL DISCRIMINATOR BETWEEN ACUTE APPENDICITIS AND OTHER PATHOLOGIES IN THE PAEDIATRIC EMERGENCY DEPARTMENT?}

\author{
J.-A. Maney ${ }^{1}$, W. McCallion²
}

${ }^{1}$ Emergency Department, ${ }^{2}$ Consultant Paediatric Surgery, Royal Belfast Hospital for Sick Children, Belfast, UK

Background: The paediatric appendicitis score ${ }^{1}$ was developed in a cohort of patients in the UK. The aim of our study is to apply the scoring system to cases referred to the regional surgical service. We analysed our data to ascertain if the scoring system is useful in discriminating between acute appendicitis and other pathologies.

Method: Retrospective analysis of records of children presenting to the Royal Belfast Hospital for Sick Children with abdominal pain for a period of two weeks in November 2009. Applying the paediatric appendicitis score to cases referred to the regional surgical service.

Results: There were 57 cases identified. There were 11 surgical referrals, 6 from the emergency department and 5 transfers from district general hospitals. The p.a.s was applied to these 11 cases.

The paediatric appendicitis score identified the children with a score of 6 or greater that needed to go to theatre and 2 children had appendicectomy. Diagnosis of appendicitis was confirmed at histology. This yielded a negative appendicectomy rate of $3 \%$ in the original study ${ }^{1}$ and RBHSC has a similar rate. This has been further validated in a cohort of 849 patients. $^{2}$

Conclusion: The paediatric appendicitis score is a useful discriminator between acute appendicitis and other pathologies in this small study. It is a 